\title{
Some ethical aspects of medical education research
}

Most likely, until midway through the $20^{\text {th }}$ century, "asking for permission" to conduct biomedical research was, at least, a very limited practice. One of the greatest acts of human madness was necessary so that, after World War II, the foundations of an ethical course of action were laid down in this field. ${ }^{1}$ A long time had to go by anyway and only in its 2000 version, the Declaration of Helsinki specifically recognized the special caution required for the participation of certain groups considered vulnerable in research. Their vulnerability refers to their limited autonomy to decide whether or not to take part in a research study.

Many advances have been made in research ethics with the strong advocacy of subjects participating in research and, at the same time, the recognition that research activities are indispensable to find evidence-based responses to the population's health problems. These basic principles, at first limited to drug research, have been slowly and progressively applied to other fields of research. ${ }^{2}$ However, there are still discussions about the ethical management in medical education, ${ }^{3}$ understood as any research involving mostly students.

We should not overlook the fact that the basic research ethical principles (beneficence, autonomy, and justice) $)^{4}$ may be easily applied to education research. Of course, also, like in any other type of research, we must start from the premise that it is fully justified due to its contribution to the advancement of knowledge.

In spite of what some authors have suggested, ${ }^{5}$ we cannot ignore that students, as subjects of research, should be considered a vulnerable population. There is no denying that the hierarchy usually established in the education field between those who conduct assessments and those who are assessed may affect the autonomy of the latter.

Finally, although according to clinical research standards, medical education research may be considered of very low risk, ${ }^{5}$ very often it involves data management, many of which may be regarded as sensitive. We cannot ignore the fact that, at present, it involves personal data exposure. ${ }^{6}$

This is particularly relevant when using an increasingly common tool: Web-based surveys. Giving way to the temptation of quickly accessing a wide population and obtaining responses in a remote, coded manner many times makes medical education researchers resort to online surveys, overestimating theirs advantages and often ignoring their limitations ${ }^{7}$ and risks. ${ }^{8}$ What is even worse, such temptation usually makes them overlook all ethical considerations, including those inherent to the use of this particular tool. ${ }^{9}$

Taking into account the premises mentioned above and in an attempt to outline a framework of reference for the ethical review of medical education research, ${ }^{5}$ we may establish some points: 1. Research should be fully and scientifically justified.

2. Projects should be assessed by a research ethics committee.

3. If it involves students, medical education research should be regarded as carried out in a vulnerable population.

4. If it involves prospective data collection, subjects should give their duly informed consent to participate, considering and respecting their decision.

5. The consent procedure should include the provision of all the information about the research so that the subject may make a decision.

6. If the research involves the management of information available as a result of a current education activity where subjects participate, and the adequate dissociation of any personally identifiable information is granted, no informed consent is required. However an ethics research committee should verify the adequacy of the dissociation method used in the project and grant a consent waiver.

7. If research is based on publicly available data, there is no need for a research ethics committee assessment, although its opinion is always desirable.

Based on these premises, scientific publications should deal with manuscripts on medical education using the same standards applied to the rest of the material they receive, ${ }^{10}$ therefore, they should demand the intervention of research ethics committees and probably the registration of the project in advance.

For any type of research to be valid, it should follow the highest scientific and ethical standards. Medical education research is not an exception to this general rule. 
Fernando Ferrero, M.D.

Hospital General de Niños "Pedro de Elizalde,"

Buenos Aires

http: / / dx.doi.org/10.5546/ aap.2018.eng.384

To cite: Ferrero F. Some ethical aspects of medical education research. Arch Argent Pediatr 2018;116(6):384-385.

\section{REFERENCES}

1. Tribunal Internacional de Núremberg. Código de Nüremberg. Nüremberg, 1947. [Accessed on: June 15 ${ }^{\text {th }}, 2018$ ]. Available at: http: / / www.bioeticanet.info/ documentos / Nuremberg.pdf.

2. Norris A, Jackson A, Khoshnood K. Exploring the Ethics of Observational Research: The Case of an HIV Study in Tanzania. AJOB Prim Res. 2012; 3(4):30-9.

3. Ten Cate $\mathrm{O}$. Why the ethics of medical education research differs from that of medical research. Med Educ. 2009; 43(7):608-10.

4. National Commission for the Protection of Human Subjects of Biomedical and Behavioral Research. The Belmont Report: Ethical Principles and Guidelines for the Protection of Human Subjects of Research. Bethesda, Md: The
Commission, 1978. [Accessed on: June $15^{\text {th }}, 2018$ ]. Available at: https: / / www.hhs.gov/ohrp/sites/default/files / the-belmont-report-508c_FINAL.pdf.

5. Eikelboom JI, ten Cate OT, Jaarsma D, et al. A framework for the ethics review of education research. Med Educ. 2012; 46(8):731-3.

6. Adams M. Big Data and Individual Privacy in the Age of the Internet of Things. TIM Review. 2017; 7(4):12-24.

7. Wright K. Researching Internet-Based Populations: Advantages and Disadvantages of Online Survey Research, Online Questionnaire Authoring Software Packages, and Web Survey Services. J ComputMediatCommun. 2005;10(3):JCMC1034. [Accessed on: June 27 ${ }^{\text {th }}, 2018$ ]. Available at: https:/ / academic.oup.com/jcmc/article/10/3/ JCMC1034/4614509.

8. Cox J. Hackers Steal 6 Million User Accounts for Cashfor-Surveys Site. Motherboard [Internet]. [Accessed on: July $\left.3^{\text {rd }}, 2018\right]$. Available at: https://motherboard.vice. com/en_us/article/bj8pvq/hackers-steal-6-million-useraccounts-for-cash-for-surveys-site.

9. Partners Human Research Committee. Guidance on Research Using the Internet. Survey Research Using WebBased Survey Tools. [Accessed on: June 27 $7^{\text {th }}, 2018$ ]. Available at:https: / / www.partners.org/ Assets / Documents / Medical-Research/Clinical-Research/Survey-Research-UsingWeb-based-Tools.pdf.

10. Eva KW. Research ethics requirements for Medical Education. Med Educ. 2009; 43(3):194-5. 